\title{
Central nervous system dysfunction and erythrocyte guanosine triphosphate depletion in purine nucleoside phosphorylase deficiency
}

\author{
H A SIMMONDS, L D FAIRBANKS, G S MORRIS, G MORGAN, A R WATSON, P TIMMS, \\ AND B SINGH \\ Purine Laboratory, Guy's Hospital, London, Department of Immunology, Institute of Child Health, \\ London, Department of Paediatrics, City Hospital, Nottingham, Department of Paediatrics and Chemical \\ Pathology, National Guard King Khalid Hospital, Jeddah, Saudi Arabia
}

SUMmARY Developmental retardation was a prominent clinical feature in six infants from three kindreds deficient in the enzyme purine nucleoside phosphorylase (PNP) and was present before development of T cell immunodeficiency. Guanosine triphosphate (GTP) depletion was noted in the erythrocytes of all surviving homozygotes and was of equivalent magnitude to that found in the Lesch-Nyhan syndrome (complete hypoxanthine-guanine phosphoribosyltransferase (HGPRT) deficiency). The similarity between the neurological complications in both disorders indicates that the two major clinical consequences of complete PNP deficiency have differing aetiologies:

(1) neurological effects resulting from deficiency of the PNP enzyme products, which are the substrates for HGPRT, leading to functional deficiency of this enzyme.

(2) immunodeficiency caused by accumulation of the PNP enzyme substrates, one of which, deoxyguanosine, is toxic to $\mathrm{T}$ cells.

These studies show the need to consider PNP deficiency (suggested by the finding of hypouricaemia) in patients with neurological dysfunction, as well as in T cell immunodeficiency. They suggest an important role for GTP in normal central nervous system function.

Deficiency of the enzyme purine nucleoside phosphorylase (PNP:EC 2.4.2.1) was first reported in 1975 in a child with recurrent infection and anaemia. ${ }^{1}$ Clinical features in the first nine cases $^{2-4}$ have invariably been related to a pronounced reduction in $T$ cell numbers and function, with either normal or enhanced $B$ cell function. ${ }^{1-7}$ Deoxyguanosine triphosphate (dGTP) has been found in the erythrocytes and implicated in the $T$ cell dysfunction of the disorder. ${ }^{2-5}$ The age at presentation has varied from birth to 6 years. Therapeutic approaches to restore immune competence have usually been unsuccessful. ${ }^{2-5}$ Most patients have died from viral infection or lymphoma. ${ }^{1-9}$ Successful engraftment after haploidentical bone marrow transplantation has been reported recently in a single case. ${ }^{10}$

This paper compares clinical and biochemical findings in our latest case of PNP deficiency with those in two previous kindreds ${ }^{5}$ and highlights severe developmental retardation as a prominent clinical feature of the disorder. We have also found severe guanosine triphosphate (GTP) depletion in the red cells of all available homozygotes from these kindreds, ${ }^{5911}$ in addition to the dGTP accumulation noted earlier by others. ${ }^{2-4}$ As the brain has a high requirement for $\mathrm{GTP}^{12}$ and resembles the human erythrocyte (Fig. 1) in being largely dependent on salvage to maintain GTP concentrations the combined clinical and biochemical findings support a direct relation between the enzyme defect and the neurological dysfunction. They underline the fact that PNP deficiency should be suspected in children with central nervous system (CNS) disorders as well as $\mathrm{T}$ cell immunodeficiency and suggest a metabolic basis for this association. 


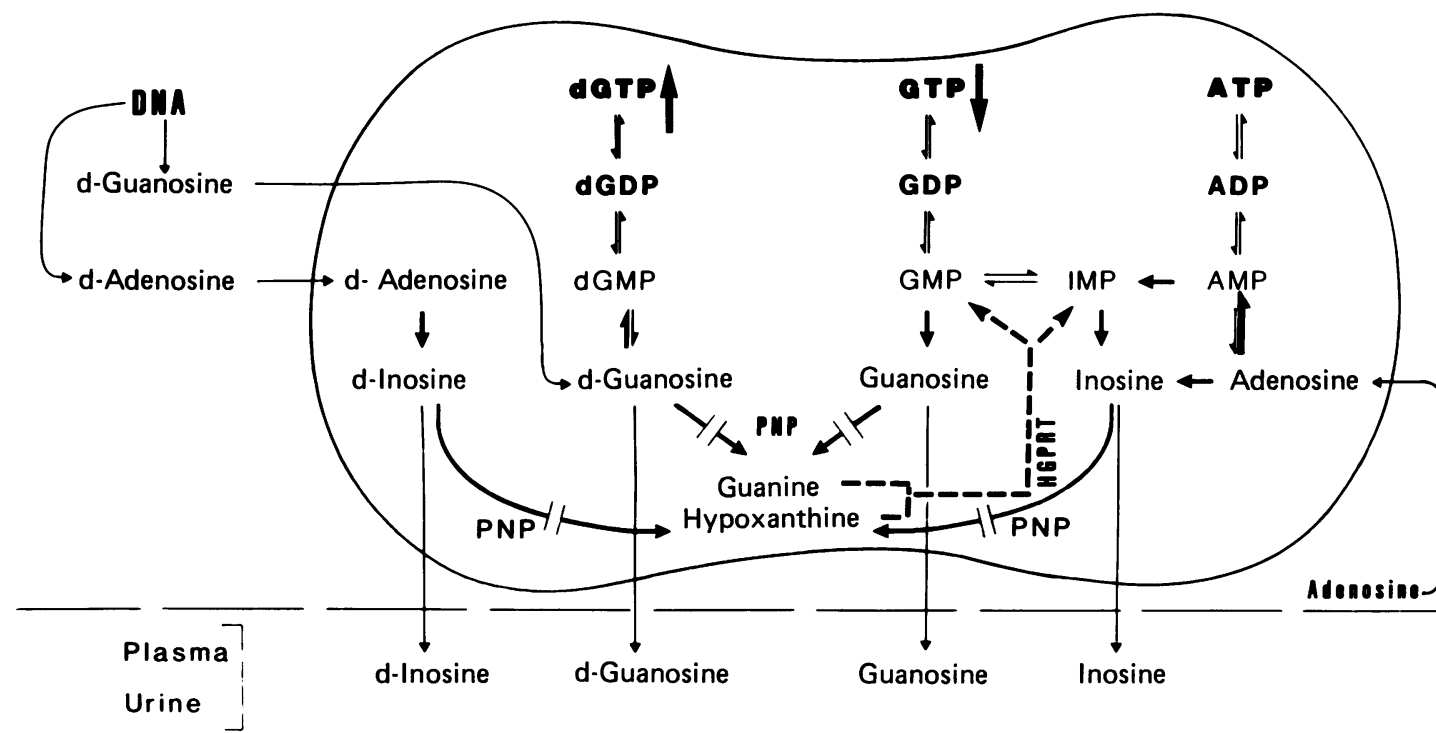

Fig. 1 Pathways of purine metabolism, indicating the importance of PNP for the degradation of deoxyribonucleosides derived from the turnover of DNA, as well as ribonucleosides arising from ATP and GTP (all shown in bold) during daily cell turnover. In the absence of PNP (broken arrows) the four PNP substrates indicated accumulate in the plasma and are excreted in urine in place of uric acid. The potential for dGTP formation after deoxyguanosine accumulation when PNP is defective is also shown.

The effect of complete PNP deficiency in restricting substrate availability for HGPRT is evident from the broken line, showing that HGPRT normally plays a vital role in tandem with PNP for guanine recycling and maintenance of GTP concentrations, particularly when de novo synthesis is absent, as in the human erythrocyte, or limited, as in the brain. The importance of extracellular adenosine, and hence adenosine kinase, for maintaining ATP concentrations in the red cell, due to a lack of the normal route of ATP formation from IMP present in nucleated cells, is also indicated.

$\mathrm{PNP}=$ Purine nucleoside phosphorylase; $\mathrm{DNA}=$ deoxyribonucleic acid; $\mathrm{ATP}=$ adenosine triphosphate; $\mathrm{ADP}=$ adenosine diphosphate; $\mathrm{AMP}=$ adenosine monophosphate; GTP=guanosine triphosphate; GDP=guanosine diphosphate; $G M P=$ guanosine monophosphate; dGTP=deoxyguanosine triphosphate; $\mathrm{dGDP}=$ deoxyguanosine diphosphate: $\mathrm{dGMP}=$ deoxyguanosine monophosphate; HGPRT=hypoxanthine-guanine phosphoribosyltransferase; IMP=inosine monophosphate; $d-=$ deoxy.

\section{Patients and methods}

\section{Case reports.}

\section{Family 1}

The propositus (case 1) in this family was the first son of healthy Irish parents who were fourth cousins. A full clinical history has been reported. ${ }^{8}$ In brief, the infant had considerable developmental delay before an aseptic meningitis at 2 years, from which he made a full recovery. At 2 years 8 months he presented with an illness similar to glandular fever. He was unable to walk unsupported and had a crude hand grasp and delayed speech. A spastic tetraparesis was clinically evident. He died of malignant lymphoma of the immunoblastic type shortly after PNP deficiency was defined.

A second boy (case 2) was born in June 1980 and PNP deficiency was confirmed at birth. He was kept under close clinical observation while different treatments were given in an attempt to ameliorate the progressive immunodeficiency. ${ }^{5}$ Excessive head lag and irritability were noticeable by 3 months. Extensive neurological investigation revealed no organic lesion or viral infection. The infant thereafter remained profoundly hypotonic with developmental delay in all spheres. Hypertonicity of the lower limbs developed before his death at 2 years from an acute para-influenza type 111 infection with pneumonia. There was no structural brain lesion at postmortem examination.

\section{Family 2}

The propositus (case 3) was an Arab girl, the sixth child of parents who were first cousins. Full details are given elsewhere. "She presented with anaemia of seven days' duration at 4 years in January 1985. A spastic tetraparesis was noted. Developmental delay was first investigated at 1 year. General physical examination showed hypertonia and exaggerated tendon reflexes, involving all limbs. An intention 
tremor was also present. There was severe developmental retardation, with motor involvement (equal to a child of 1 year) being more severe than intellectual development (equivalent to a child of 2.5 years). The child had started to sit at 1 year and stand at 3 years and walked unsteadily on tiptoe with help at 3 years 9 months. Investigations showed a child with anaemia with a positive result of a direct Coombs test and severe T cell immunodeficiency. ${ }^{9}$ A computed tomogram of the brain and electroencephalogram yielded normal results. The child subsequently succumbed to viral infection at the age of 4 years 6 months. Permission for postmortem examination was refused.

Family history revealed an elder sister (case 4) who had died at 4 years of chickenpox complicated by pneumonia and carditis and had also been severely developmentally retarded and suffered repeated chest and ear infections. (She was considered a homozygote for PNP deficiency from the similarity in the case history). An 11 month old brother (case 5) showed similar abnormalities to the propositus: CNS involvement was evident from poor head control, generalised hypotonia with inability to stand, and a delay in fine motor milestones. Only limited investigations were permitted, but retardation remains the principal problem. Despite the severe $\mathrm{T}$ cell immunodeficiency, ${ }^{9}$ there have been no episodes of infection over the past 12 months.

\section{Family 3}

The propositus in this new kindred (case 6) was the fourth child of healthy, unrelated parents. One child had died at birth. The two surviving siblings are healthy. He was noted to have mild left hemiparesis and delayed motor development aged 14 months and at the time of study was attending a special school. He presented in March 1986 at the age of 4 years 5 months with Coombs positive autoimmune haemolytic anaemia (haemoglobin $8.9 \mathrm{~g} / \mathrm{dl}$ ) and thrombocytopenia $\left(18 \times 10^{9} / 1\right)$ after the latest of a series of pulmonary infections. He was shown to have severe $T$ cell deficiency with lymphopenia and lack of mitogen and alloantigen responses; immunoglobulin concentrations were normal (IgG 8.9, IgA $0 \cdot 51$, and $\operatorname{IgM} 1.1 \mathrm{~g} / \mathrm{l})$. At this time he was making reasonable developmental progress, with the non-progressive hemiparetic cerebral palsy as his only neurodevelopmental problem. He died at 4 years 6 months of complications related to immunosuppression of graft versus host disease contracted from a platelet transfusion. Permission for postmortem examination was refused.

Biochemical methods. Purine nucleoside concentrations in plasma and urine and nucleotides in red cells were determined using a Waters (MilliporeWaters, Harrow, Middlesex, England) trimodule fully automated high pressure liquid chromatography system coupled to a $5 \mu$ APS-Hypersil column, or a $5 \mu$ Spherisorb ODS1 column $(25 \mathrm{~cm} \times 4.9 \mathrm{~mm}$, Hichrom, United Kingdom), for the separation of nucleotides, or nucleosides and bases, respectively. ${ }^{11} 13-15$ The method used for determination of PNP activities, as well as the activity of the other purine enzymes-namely, adenosine deaminase, adenine phosphoribosyltransferase, and hypoxanthine-guanine phosphoribosyltransferase (HGPRT)-in lysed red cells using high pressure liquid chromatography, has also been reported. ${ }^{14}$ Studies with 8-[14C] labelled deoxyguanosine, using intact red cells, were also carried out to exclude the possibility of a labile enzyme detectable only in intact cells (not lysed cells). They were processed using a radiodetector (Reeve Analytical, Glasgow, Scotland) coupled to the above high pressure liquid chromatography system as previously described. ${ }^{15}$ S-adenosylhomocysteine hydrolase activity was determined by the method of Kaminska and Fox. ${ }^{16}$

\section{Results}

Purine enzymes. The propositus in family 3 (case 6) was found to lack any detectable PNP activity in lysed erythrocytes, as previously found for cases 2 , 3 , and 5 (Table 1). Completeness of the enzyme defect and exclusion of the presence of a labile enzyme was confirmed by incubation of intact red cells from case 6 with $8-[14 \mathrm{C}]$ deoxyguanosine. (This showed no metabolism of substrate to guanine, although detectable amounts of deoxyguanosine triphosphate were formed. Results not shown.) Both parents and one sibling in family 3 showed heterozygote PNP activities in lysed red cells (Table 1). The results are in accordance with the recessive mode of inheritance reported in the disorder. $^{2-48}$

The presence of normal HGPRT activity in case 6 (Table 1), as in cases 2, 3, and 5, was also confirmed by studies in intact red cells (results not shown). Of the other purine enzymes, both adenine phosphoribosyltransferase and adenosine deaminase were again raised in case 6 (Table 1), a finding noted in some but not all homozygotes. ${ }^{1-7} 9$ Low S-adenosylhomocysteine hydrolase activities (patient range $1 \cdot 7-3 \cdot 0 \mathrm{nmol} / \mathrm{mg} \mathrm{Hb} / \mathrm{h}$ : control range $3 \cdot 6-9 \cdot 0 \mathrm{nmol} / \mathrm{mg} \mathrm{Hb} / \mathrm{h}$ ) were also found, as reported earlier by others in this disorder..$^{2-49} 16$ Extremely low activities of this enzyme were first noted in adenosine deaminase deficiency, the companion purine disorder presenting as severe combined 
388 Simmonds, Fairbanks, Morris, Morgan, Watson, Timms, and Singh

Table 1 Specific activities of four different purine enzymes in the parents and the surviving siblings in family 3, compared with previous results in cases 2,3 , and $5 .{ }^{5}$ Plasma and urine purine concentrations in the four homozygotes show the accumulation of the four nucleosides inosine, guanosine, deoxyinosine, and deoxyguanosine in place of uric acid

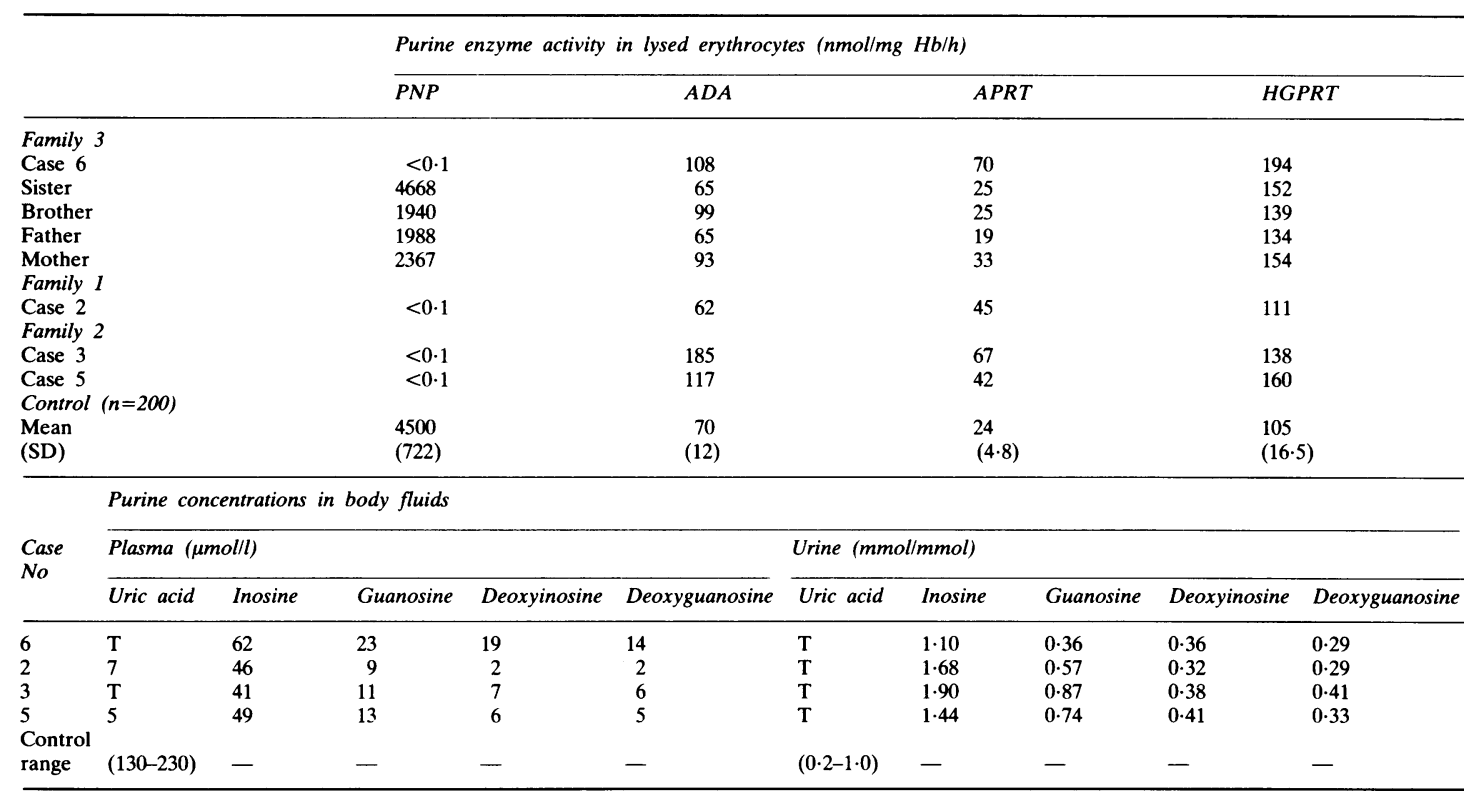

PNP=Purine nucleoside phosphorylase: ADA=adenosine deaminase; APRT=adenine phosphoribosyltransferase; HGPRT=hypoxanthine-guanine phosphoribosyltransferase.

T= Trace.

$-=$ Not normally detectable.

Table 2 Mean red cell nucleotide concentrations in the four homozygotes from the three PNP deficient kindreds compared with the mean values from 20 control children and seven patients with HGPRT deficiency, showing the correlation between GTP concentrations and the degree of neurological involvement as well as the accumulation of dGTP in PNP deficient red cells (gout/retarded=dysarthria, spastic gait, but no self mutilation)

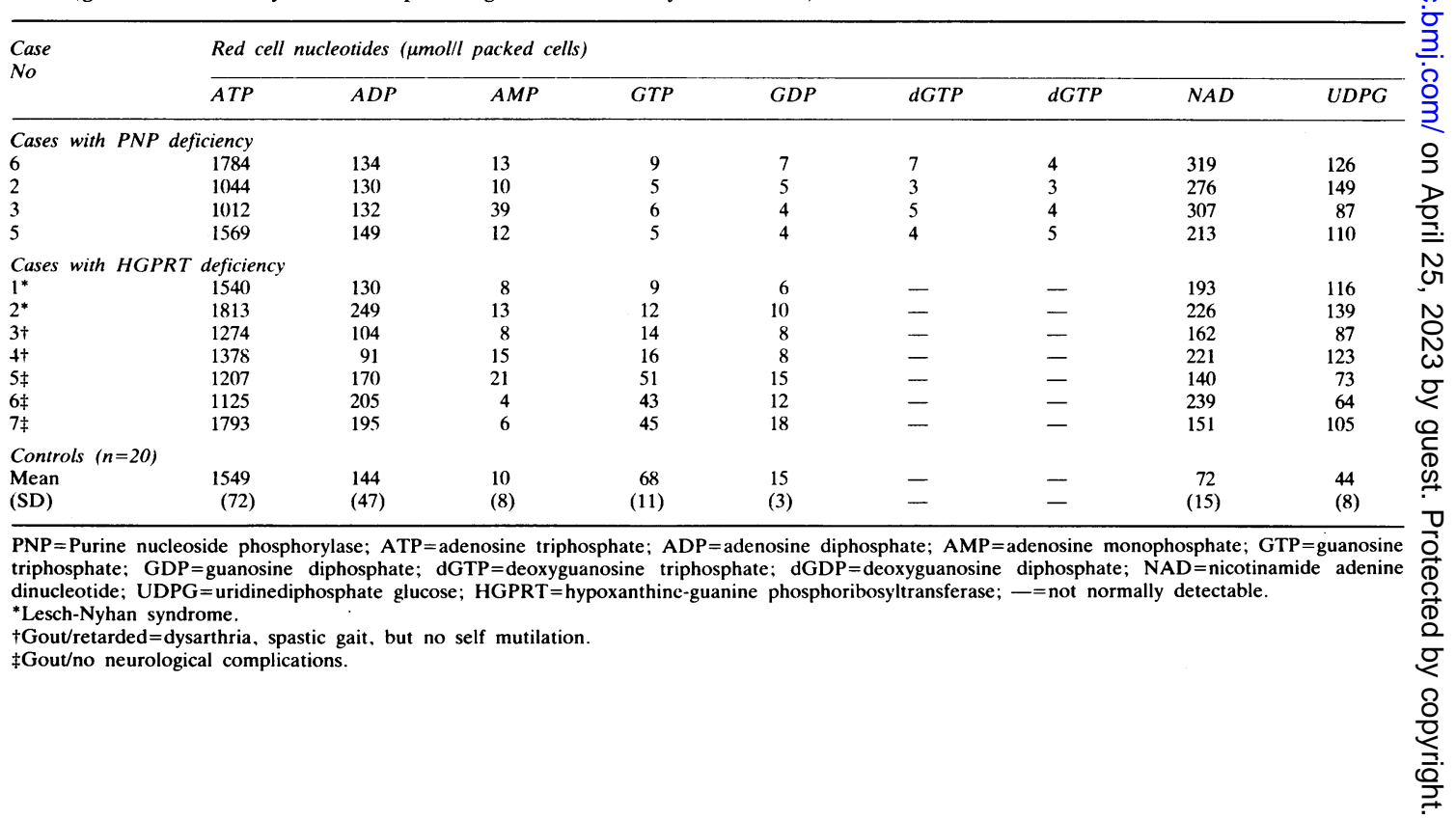


immunodeficiency, ${ }^{16-18}$ but the association, if any, with the immunodeficiency remains undefined.

Plasma and urine purine concentrations. Table 1 also shows that case 6 likewise accumulated high concentrations of the four PNP substrates, inosine, guanosine, deoxyinosine, and deoxyguanosine, in place of uric acid. The latter was virtually undetectable in both plasma and urine, confirming the completeness of the enzyme defect in all the homozygotes we studied. Excretion measured as an index of creatinine showed the purine overproduction characteristic of this disorder (three- to fourfold normal). Renal clearances relative to the glomerular filtration rate for the four nucleosides indicated net tubular secretion.

Erythrocyte nucleotide concentrations. Mean red cell nucleotide concentrations in case 6 (Table 2 , Fig. 2) showed very low guanosine triphosphate/ guanosine diphosphate concentrations, as noted earlier in cases 2,3 , and $5,{ }^{59}$ associated with raised deoxyguanosine triphosphate/deoxyguanosine diphosphate, nicotinamide adenine dinucleotide, and uridinediphosphate glucose concentrations.

Mean red cell nucleotide concentrations from patients with HGPRT deficiency are also shown in Table 2 for comparison and show that red cell GTP
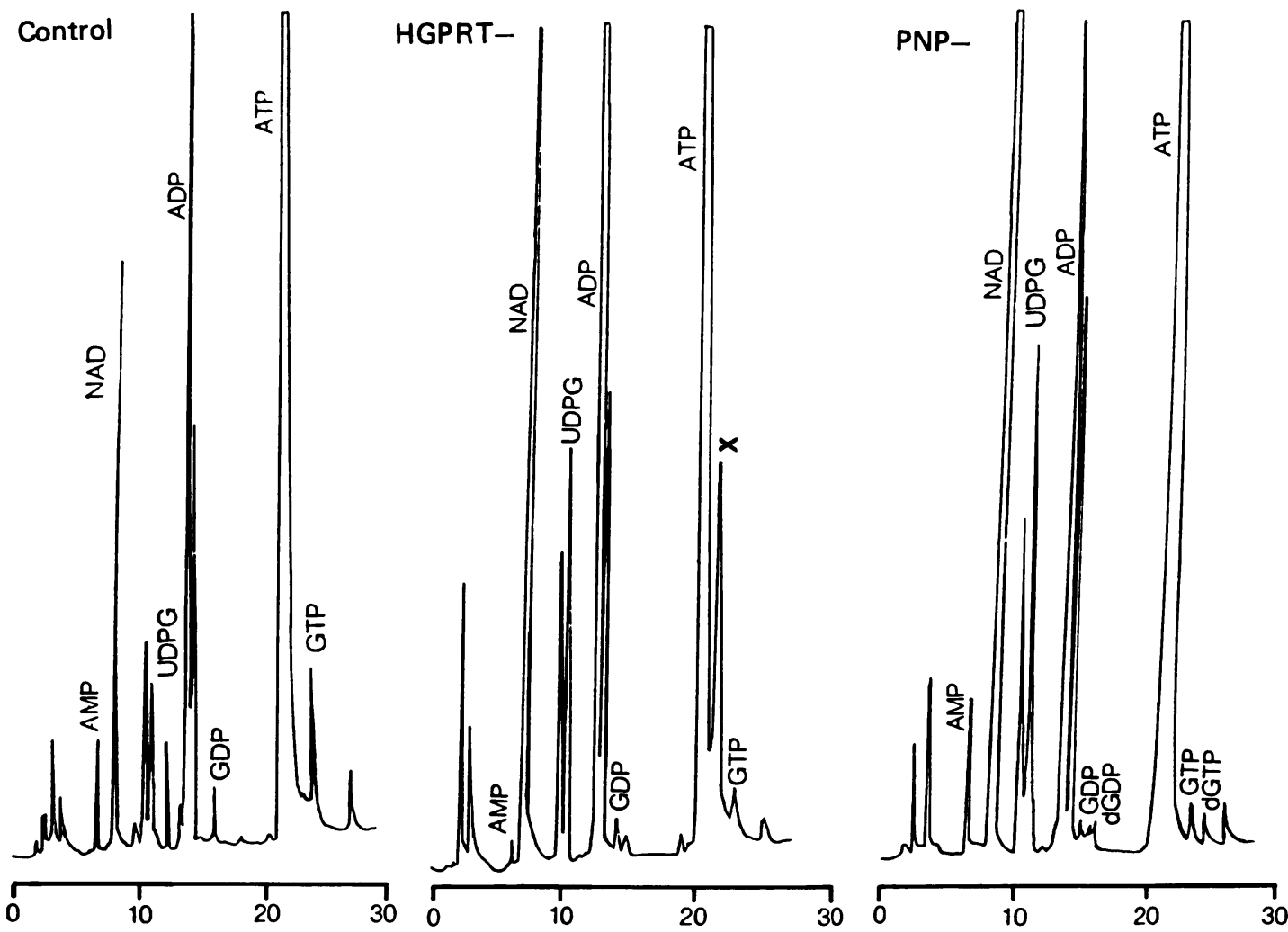

Time (mins)

Fig. 2 High performance liquid chromatography traces at $254 \mathrm{~nm}$ and 0.05 aufs after injection of $25 \mu$ of extract from the red cells of case 6 (PNP-) and a case with the Lesch-Nyhan syndrome (HGPRT-), showing the severe GTP and GDP depletion compared with the control and the presence of two additional peaks corresponding to dGDP and dGTP in the PNP deficient cells. (Peak marked $X$ in the HGPRT-cells is ZTP: 5-amino-4-imidazolecarboxamide ribotide.)

PNP=Purine nucleoside phosphorylase; HGPRT=hypoxanthine-guanine phosphoribosyltransferase; $\quad A T P=$ adenosine triphosphate; $\quad$ ADP $=$ adenosine diphosphate; $A M P=$ adenosine monophosphate; $G T P=$ guanosine triphosphate; GDP=guanosine diphosphate: dGTP=deoxyguanosine triphosphate; dGDP=deoxyguanosine diphosphate; $\mathrm{NAD}=$ nicotinamide adenine dinucleotide: $\mathrm{UDPG}=$ uridinediphosphate glucose 
depletion was likewise ${ }^{19}$ a characteristic of severe HGPRT deficiency (Lesch-Nyhan syndrome) and tended to reflect the severity of the CNS involvement. Red cell GTP depletion was not found in the four patients with partial HGPRT deficiency in whom CNS function was normal.

\section{Discussion}

The purpose of this report was to highlight the neurological abnormalities that were a prominent clinical feature in six patients from three PNP deficient families. It should be emphasised, therefore, that immunodeficiency may not be the presenting symptom in this disorder. Neurological involvement was also present in four of the first nine published cases, but it was questioned whether this was secondary to viral infection, possibly contracted by immunisation with live virus. ${ }^{2}$ Our observations indicate that CNS viral infection is an unlikely cause of the neurological deficit seen in these patients. Case 2 was investigated from birth and showed head lag and excessive irritability at 3 months. ${ }^{5}$ Our latest case had neurological problems that required attendance at a special school, well before the onset of autoimmune disease. Spastic tetraparesis was present in three siblings from the first Dutch kindred; ${ }^{2} .3$ a recent Dutch case was investigated initially for spastic diplegia and behavioural disorders, not immunodeficiency." Furthermore, neurological complications have not been present in any of the 12 children with adenosine deaminase deficiency and severe combined immunodeficiency that we have studied. ${ }^{18}$

Neurological symptoms have now been described in $50 \%$ of cases with PNP deficiency. Of the remainder, there has been no mention of CNS function in five homozygotes, ${ }^{26}$ while mild neurological problems associated with an intention tremor were noted in one case, with a total absence of neurological problems in three others. ${ }^{2}$ The four latter cases, however, had some residual PNP activity. Two further cases exist that have not been reported in detail and apparently do not have neurological involvement, but again these are in the older age group, suggesting some residual enzyme. (Hershfield MS. Personal communication.) Thus the range of neurological involvement apparently equates well with the severity of the enzyme deficiency. The other noteworthy finding in this report is that severe erythrocyte GTP depletion seems to be characteristic of PNP deficient kindreds with neurological involvement. (Zegers BJM. Personal communication.) GTP depletion has also been a consistent finding in patients with the LeschNyhan syndrome (severe HGPRT deficiency), ${ }^{19}$ but it has not been found in partial HGPRT deficiency without neurological involvement (sex linked recessive gout/urolithiasis).

These findings suggest an important link between GTP concentrations and normal CNS function. GTP is known to be essential both for sustained macromolecular synthesis and neurotransmission within the CNS. Consequently, restriction of substrate supply to HGPRT, due to defective PNP activity (Fig. 1), could be as damaging to either of these functions as a defect in HGPRT itself. This hypothesis is supported by the fact that the clinical progress of case 2 bore many similarities to that described for children with the Lesch-Nyhan syndrome, where generalised muscular hypotonia from infancy is considered to be the basic abnormality on which torsion dystonia is subsequently superimposed. ${ }^{12}$ HGPRT activity is higher in the CNS than in any other tissue, and in the neonatal period the ratio of HGPRT salvage activity to de novo synthesis increases considerably after the main burst of neuroblast and neuroglial proliferation. ${ }^{12}$ The absence of any anatomical or histopathological lesions in the brain in the Lesch-Nyhan syndrome suggests that the enzyme deficiency produces neurological dysfunction by interfering with brain function rather than brain morphogenesis. ${ }^{12}$ Extensive neurological investigation in case 2 also revealed no anatomical lesion. ${ }^{5}$ This was confirmed at postmortem examination.

The combined clinical and biochemical results suggest that CNS dysfunction in PNP deficiency is a direct consequence of the enzyme defect and relates to an inherent inability to sustain GTP at concentrations essential for normal function, with the red cell, as in HGPRT deficiency, reflecting a wider deficit in tissues, such as brain, that also depend on salvage for maintaining GTP concentrations. Whether the finding of GTP depletion and/or the associated accumulation of deoxyguanosine triphosphate in platelets as well as red cells ${ }^{9}$ is also important for the immune response is unknown. With the exception of case 6, platelet numbers have been normal, but GTP depletion in vitro has been linked with defective synthesis of deoxyribonucleic acid in lymphoid cells. ${ }^{21}$ As immunodeficiency is not a facet of the Lesch-Nyhan syndrome, however, it would seem that GTP depletion per se is not implicated in the gradual attrition of T cell function in PNP deficiency.

In summary, this study underlines the fact that immunodeficiency may not necessarily be the presenting abnormality, or of the greatest immediate concern to the family, in patients with PNP deficiency. The enzyme defect should be considered in children with developmental delay and neurological dysfunction. Autoimmune haemolytic anaemia is 
also a recognised mode of presentation. ${ }^{29}$ The diagnosis is suggested by the finding of hypouricaemia. Measurement of PNP activity and purine concentrations in body fluids will be essential to confirm the metabolic basis for the defect, ${ }^{21}$ while red cell GTP concentrations may be a useful guide to the degree of CNS involvement. The studies also indicate that there may be potential hazards associated with the development of PNP inhibitors as immunosuppressants for different malignant states.

This study was supported by the Medical Research Council and the Wellcome Trust.

\section{References}

1 Giblett ER, Ammann AJ, Wara DW, Sandman R, Diamond LK. Nucleoside phosphorylase deficiency in a child with severely defective T-cell immunity and normal B-cell immunity. Lancet 1975;i:1010-3.

2 Ammann AJ. Immunological aberrations in purine nucleoside phosphorylase deficiencies. In: Enzyme defects and immune dysfunction. Amsterdam: Excerpta Medica, 1979: 55-75. (Ciba Foundation Symposium, No 68.)

${ }^{3}$ Stoop JW, Zegers BJM, Kuis W, et al. Purine nucleoside phosphorylase deficiency: long-term clinical, immunological and metabolic follow-up. In: Seligman M, Hitzig W, eds. Primary immunodeficiencies. North Holland: Elsevier, 1980: 301-11. (INSERM Symposium 16.)

+ Hirschorn R. Genetic deficiencies of adenosine deaminase and purine nucleoside phosphorylase: overview, genetic heterogeneity and therapy. Birth Defects 1983;19:73-81.

5 Watson AR, Simmonds HA, Webster DR, Layward L, Evans DIK. Purine nucleoside phosphorylase (PNP) deficiency: a therapeutic challenge. In: De Bruyn CHMM, Simmonds HA, Muller MM, eds. Purine metabolism in man IVA. New York: Plenum, 1984:53-9.

- Zabay JM, De La Concha EG. Ludena C, et al. B cell hyperactivity and abnormalities in $T$ cell markers and immunoregulatory function in a patient with nucleoside phosphorylase deficiency. Clin Exp Immunol 1982:50:610-6.

7 Rijksen G. Zegers BJM, Spaapen LJM, et al. Residual purine nucleoside phosphorylase activity in a new Dutch patient with PNP-deficiency and cellular immunodeficiency. Peditar Res 1986;195:772.

* Watson AR, Evans DIK, Marsden HB, Miller V, Rogers PA. Purine nucleoside phosphorylase deficiency associated with a fatal lymphoproliferative disorder. Arch Dis Child 1981;56: 563-5.

"Simmonds HA, Fairbanks LD, Morris GS, Timms P. Singh B. Bold A. Erythrocyte GTP depletion in PNP deficiency presenting with hacmolytic anaemia and hypouricaemia. In: Nyhan
WL, Thompson LF, Watts RWE, eds. Purine and pyrimidine metabolism in man VA. New York: Plenum. 1986:481-6.

1" Buckley RH. Schiff SE. Sampson HA, et al. Development of immunity in severe primary $\mathrm{T}$ cell deficiency following haploidentical bone marrow stem cell transplantation. J Immunol 1986:136:2398-407.

1 Simmonds HA, Watson AR. Webster DR. Sahota A. Perrett D. GTP depletion and other erythrocyte abnormalities in inherited PNP deficiency. Biochem Pharmacol 1982:31:941-6.

12 Watts RWE, Spellacy E. Gibbs DA. Allsop J, Mckeran RO, Slavin GE. Clinical, post mortem, biochemical and therapeutic observations on the Lesch-Nyhan syndrome with particular reference to the neurological manifestations. $Q J$ Med 1982:201: 43-78.

13 Morris GS. Simmonds HA. Use of a fundamental elution protocol for the development of a reverse phase HPLC method enabling rapid simultaneous determination of purine, pyrimidines and allied compounds in biological fluids. J Chromatogr 1985:344:101-13.

14 Fairbanks LD, Goday A, Morris GS, Brolsma MFJ, Simmonds HA. Gibson T. Rapid determination of purine enzyme activity in intact and lysed cells using high-performance liquid chromatography with and without radiolabelled substrates. I Chromatogr 1983;276:427-32.

15 Simmonds HA. Goday A. Morris GS. Fairbanks LD, Levinsky RJ. dATP accumulation and ATP depletion in platelets in adenosine deaminase deficiency: significance for the immune response? Biosci Rep 1984:4:809-14.

16 Kaminska JE. Fox IH. Decreased S-adenosylhomocysteine hydrolase in inborn errors of purine metabolism. J Lab Clin Med 1980:96:141-7.

17 Hershfield MS, Kredich NM, Ownby H, Buckley R. In vivo inactivation of erythrocyte $\mathrm{S}$-adenosylhomocysteine hydrolase by 2 'deoxyadenosine in adenosine deaminase deficient patients. $J$ Clin Invest 1979:63:807-11.

${ }^{18}$ Simmonds HA, Fairbanks LD, Morris GS, Webster DR, Morgan G, Levinsky RJ. Correlations between purine levels, clinical and immunological status in ADA deficiency. In: Nyhan WL, Thompson LF. Watts RWE. eds. Purine and pyrimidine metabolism in man VA. New York: Plenum, 1986:93-101.

${ }^{19}$ Simmonds HA, Webster DR, Watson AR, Barratt TM, Wilson J. Erythrocyte GTP depletion associated with severe muscular hypotonia in three inherited disorders of purine metabolism. Clin Sci 1982:63:61.

20) Cohen MB, Maybaum J, Sadee W. Guanine nucleotide depletion and toxicity in mouse T lymphoma (S-49) cells. J Biol Chem 1981:256:8713-7.

${ }^{21}$ Horowitz SD, Borcherding W, Hong R. Autoimmune haemolytic anaemia as a manifestation of T-suppressor-cell deficiency. Clin Exp Immunol 1984;33:313-23.

Correspondence to Dr H A Simmonds, Purine Research Laboratory, Guy's Tower (17th and 18th Floors), Guy's Hospital, London SE1 9RT.

Received 1 December 1986 